\title{
Correction to: Case Study and Performance Evaluation of MDMA-A Non-orthogonal Multiple Access Scheme for 5G Cellular Systems
}

\author{
Wei-Han Hsiao ${ }^{1}$ Y Yung-Wen Shih ${ }^{1} \cdot$ Chia-Chi Huang ${ }^{1}$
}

Published online: 11 January 2018

(C) Springer Science+Business Media, LLC, part of Springer Nature 2018

\section{Correction to: Mobile Netw Appl}

https://doi.org/10.1007/s11036-017-0970-2

The original version of this article unfortunately contained mistakes in Table 1, Footnote 11, and Eqs. 2, 4, 6, 21, 23, $24,25,29,34,36$, and 38 .

The original version has been corrected.

The online version of the original article can be found at https://oi.org/ 10.1007/s11036-017-0970-2

Wei-Han Hsiao

whsiao.cm97g@g2.nctu.edu.tw

1 Department of Electrical and Computer Engineering, National Chiao Tung University, Taiwan, Republic of China 